\title{
Capital Utilization, Economic Growth and Convergence
}

\author{
Santanu Chatterjee* \\ Department of Economics \\ Terry College of Business \\ University of Georgia \\ Athens, GA 30602-6254
}

\footnotetext{
*Email: schatt@terry.uga.edu. Voice: +1-706-542-3696, Fax: +1-706-542-3376.
} 


\title{
Capital Utilization, Economic Growth and Convergence
}

\begin{abstract}
This paper examines the implications of capital utilization for the dynamics of growth and convergence. Optimal decisions by economic agents regarding the utilization of capital lead to empirically plausible speeds of convergence in one-sector models of economic growth, thereby providing a simpler alternative to the adjustment costs and multiple capital goods frameworks. The sensitivity of depreciation to capital utilization leads to "less than full" utilization of capital by the economic agent, a result consistent with empirical facts. The relationship between the rate of depreciation and capital utilization, embodied in the variable marginal benefits and costs of capital accumulation along the transition path, plays a crucial role in slowing down the speed of convergence to the steady state. By assuming a constant depreciation rate and full capital utilization, standard growth models may be significantly overstating the magnitude of the steadystate equilibrium. Finally, differences across countries in the extent to which agents internalize the capital utilization decision along the transition path may lead to differences in the speed of adjustment to the steady-state equilibrium, even for countries that have similar structural and initial conditions.
\end{abstract}

JEL Classification: D9, E0, E2.

Keywords: Economic growth, capital utilization, speed of convergence, depreciation. 


\section{Introduction}

This paper examines the implications of capital utilization for the dynamics of growth and convergence. First, we show how optimal decisions regarding the utilization of capital can lead to empirically plausible speeds of convergence in one-sector models of economic growth. Second, our analysis suggests that by ignoring the capital utilization decision, standard growth models may be significantly overstating the magnitude of the steady-state equilibrium. Finally, our numerical analysis suggests that differences across countries in the extent to which agents internalize the capital utilization decision along the transition path may lead to differences in the speed of adjustment to the steady-state equilibrium, even for countries that have similar structural and initial conditions.

The concept of capital utilization as an optimal decision is not new to the macroeconomics literature and, in fact, dates back to the early work of Keynes (1936). In developing the notion of "user cost," Keynes pointed out that "user cost constitutes the link between the present and the future. For in deciding his scale of production an entrepreneur has to exercise a choice between using up his equipment now or preserving it to be used later on....". ${ }^{1}$ This observation captures both the essence and importance of capital utilization for the dynamics of growth. A more intense utilization of the existing capital stock would cause higher wear and tear and, as a consequence, increase depreciation costs. This in turn would affect new investment in the future. This insight has been used by Lucas (1970), Smith (1970), Taubman and Wilkinson (1970), Calvo (1975), and Oi (1981) to understand and explain investment behavior and business cycles. More recently, the concept of capital utilization has found wider application in the context of the real business cycle literature; see Greenwood, Hercowitz, and Huffman (1988), Burnside, Eichenbaum, and Rebelo (1996), and Wen (1998).

Although capital accumulation has been assigned a central role in explaining economic growth, little attention has been paid to the implications of the capital utilization decision for the

\footnotetext{
${ }^{1}$ J.M. Keynes (1936, pp. 69-70); also quoted in Greenwood et al. (1988).
} 
dynamics of long-run growth. ${ }^{2}$ Defining capital utilization as the speed or intensity with which a given stock of capital equipment is operated (for example, the "workweek" of capital), we can identify two important channels through which capital utilization affects the intertemporal growth path of an economy. First, the flow of output depends not only on the existing stock of capital, but also on the flow of services derived from it, through the firms' decision on the intensity (say, length of time) with which that capital stock must be used. Therefore, the capital utilization decision provides the firm with an extra margin to change output. Second, the rate of depreciation depends on the degree of utilization of the capital stock, and is therefore endogenously determined. Specifically, the higher the rate of capital utilization, the higher will be the associated wear and tear of the capital stock, and the higher will be the rate of depreciation. This idea is in sharp contrast to the existing growth literature, which treats the rate of depreciation as a constant and assumes that the flow of capital services is a constant proportion of the underlying capital stock. A constant depreciation rate implies a zero marginal cost of capital utilization, and therefore it is always optimal for the agent to fully utilize capital. ${ }^{3}$ In contrast, in the capital utilization model, optimal behavior by the economic agent causes the marginal cost of utilization to change along with the marginal product of the underlying capital stock being accumulated. This affects not only the rate at which the economy is approaching the steady-state equilibrium, but also the transitional path of new investment and hence future output, as the marginal benefits must be weighed against the marginal costs.

Several authors, including Foss (1963), Marris (1964), Nadiri and Rosen (1969), and Beaulieu and Mattey (1998), have empirically documented that the rate of capital utilization exhibits a dynamic adjustment process. Moreover, contrary to the assumptions of theoretical growth models, these authors have presented evidence that there is less than full utilization of capital and that the flow of capital services is not a fixed proportion of the underlying capital

\footnotetext{
${ }^{2}$ A few notable exceptions are Marris (1964) and Betancourt and Clague (1981).

${ }^{3}$ The constancy of the depreciation rate is a debatable issue. Empirical studies by Epstein and Denny (1980), and Kollintzas and Choi (1985) have reported variable depreciation rates; see Nadiri and Prucha (1996) for a survey of this literature.
} 
stock. ${ }^{4}$ Foss (1981a,b, 1995) finds that the average workweek of capital in the U.S. increased about 25 percent between 1929-76, and by 8.1 percent over 1976-88. Similar upward trends have also been documented by Taubman and Gottschalk (1971), Orr (1989), and Beaulieu and Mattey (1998). ${ }^{5}$ Estimates of capital utilization also vary across time and industries. For example, Shapiro (1986) and Orr (1989) report that the average workweek of capital in U.S. manufacturing over the 1952-82 period was slightly above 50 hours per week (out of a maximum of 168 hours), with a corresponding capital utilization rate of about 30 percent. On the other hand, Beaulieu and Mattey (1998) estimate the average workweek to be 97 hours over the period 1974-92, yielding a capital utilization rate of about 58 percent. They also report a great deal of variation across industries, with apparel having the lowest utilization rate of 26.5 percent, while petroleum refining had the highest rate of 93.5 percent.

As mentioned earlier, in contrast to the empirical evidence discussed above, the theoretical growth literature is based on models that assume a constant depreciation rate and hence full or at best, constant, capital utilization. Based on these assumptions, the debate on convergence in the growth literature has mainly revolved around two issues. The first is the speed of convergence, i.e., the rate at which the gap between a country's current and steady-state per-capita output is being closed. The second is the nature of the convergence path, and concerns cross-country differences in growth rates and standards of living and whether these differences show tendencies to diminish or increase over time.

Numerical calculations based on the standard one-sector neoclassical Ramsey model and the two-sector Lucas (1988) endogenous growth model suggest fairly high speeds of convergence, between 7 and 10 percent. However, empirical estimates of the speed of convergence contrast sharply to that implied by theory. Estimates obtained in the recent

\footnotetext{
${ }^{4}$ Foss (1963) notes that the capital stock in U.S. manufacturing has been idle most of the time, even in periods of economic prosperity. Marris (1964) provides similar evidence for the U.K., and argues that much of the observed idleness reflects the ex-ante intention to leave capital idle, owing to higher expected operating costs.

${ }^{5}$ Even for individual industries, the variation of the capital utilization rate over time is significant. Cardellichio (1990), Aizcorbe (1994), and Bresnahan and Ramey $(1993,1994)$ find large changes in plant work periods in the lumber and auto industries.
} 
influential works of Barro and Sala-i-Martin (1992, 1995), Mankiw, Romer and Weil (1992), and Sala-i-Martin $(1994,1996)$ fall in the range of 2-3 percent, thereby implying much slower adjustment to the steady state than implied by theoretical models. The theoretical literature has attempted to reconcile this discrepancy between models and evidence by introducing various additional sources of sluggishness that reduce the implied speed of convergence. For example, Ortiguera and Santos (1997) introduce convex adjustment costs of installing capital in a twosector endogenous growth model with physical and human capital. Eicher and Turnovsky (1999a, b) and Turnovsky (2003) introduce a second capital good, in the form of knowledge or public capital, into a generalized version of the neoclassical model. These modifications, however, are not without limitations. The adjustment cost framework has been subject to criticisms regarding its empirical relevance (Kydland and Prescott, 1982), and the introduction of multiple capital goods or sectors often leads to analytically complex models (Turnovsky, 2000). However, the fact remains that standard one-sector models of growth, without the above additional sources of sluggishness, generate implausibly fast speeds of convergence. ${ }^{6}$

This paper attempts to develop a simple framework for analyzing the dynamics of growth and convergence consistent with empirical evidence. By introducing capital utilization as an optimal decision, we show that one-sector neoclassical and endogenous growth models can generate speeds of convergence in line with recent empirical evidence. Therefore, this reduces the need to incorporate additional sources of sluggishness like adjustment costs or multiple capital goods. However, our aim is not to criticize the above modifications, but to provide a much simpler alternative based on optimal choice that helps us resolve the issue. Our numerical analysis suggests that by not allowing depreciation to be sensitive to capital utilization, the standard growth model may be overstating the magnitude of the long-run equilibrium. Moreover, the equilibrium values of the endogenous depreciation and capital utilization rates generated by

\footnotetext{
${ }^{6}$ Some recent studies have criticized the empirically estimated speed of convergence of 2-3 percent on the ground that it ignores a number of econometric issues. Notable among these are Islam (1995), Caselli, Esquivel, and Lefort (1996), Evans (1997), and Temple (1998). These studies estimate the speed of convergence in the range of 4-6 percent, thereby suggesting a downward bias in earlier estimates. However, even these recent estimates are lower than those suggested by theoretical models.
} 
our numerical simulations are also consistent with their corresponding empirical estimates, thereby underscoring the importance of capital utilization for economic growth.

The nature of the convergence path throws light on the key determinants of economic growth, both over time and across countries. A sizeable literature has explored the possibilities of conditional convergence, i.e., countries converging to common per-capita income levels. ${ }^{7}$ We illustrate how the internalization of the capital utilization decision may explain conditional convergence. We extend the notion of conditional convergence by illustrating the possibility of two structurally similar countries, with similar initial conditions, approaching a common longrun equilibrium at different speeds of adjustment, depending on their underlying differences in the costs and benefits of capital utilization along the transition path. These differences may arise due to institutional factors governing the choice of multiple shifts in production (as in Europe), capital-labor ratios across industries and shifts, the vintage of the underlying capital stock, and the workweek of labor. Empirical evidence on capital utilization rates across countries is sparse, but the few studies that do exist document significant variation in cross-country utilization rates. For example, using survey data from 1971-72, Bautista et al. (1981) find that capital utilization rates in Colombia, Israel, and Malaysia were 42.6, 38.4, and 54.6 percent respectively. In a similar study for ten European Community (EC) countries, Anxo et al. (1995) report a large variation in utilization rates across Europe. For example in 1989, Germany had the lowest capital utilization rate at 31.5 percent, and Belgium had the highest at 45.8 percent, while the average for all of Europe was about 39 percent. They also report much higher capital utilization rates in U.S. manufacturing industries than in Europe.

\section{The Analytical Framework}

We consider an infinitely lived representative agent who maximizes lifetime utility from consumption. The agent also produces output, which can be costlessly transformed into a

\footnotetext{
${ }^{7}$ Barro (1991) and Sala-i-Martin (1996) find evidence of conditional convergence, explanations of which have included variations in the level of technological progress (Bernard and Jones, 1996), its diffusion across countries and over time (Barro and Sala-i-Martin, 1997), and endogenous obsolescence of capital goods (Hsieh, 2001).
} 
consumption good and investment. The agent optimally chooses the rate of consumption, investment, and the rate of capital utilization, given the stock of available capital at that instant. There is no government in this economy.

\subsection{Production}

Production at any instant takes place by means of the flow of services derived from the available capital stock at that instant. In other words, the agent's production and investment decisions take place through the following two channels. First, at any instant, the optimal choice of investment determines the rate of accumulation of new capital. Second, given the available stock of capital, $K$, the agent chooses the rate of utilization of that stock, $u$. Following Taubman and Wilkinson (1970) and Calvo (1975), we can define the rate of utilization as the intensity (say, the number of hours per day) with which the available stock of capital is utilized. We also assume that the rate of depreciation of capital is an increasing function of the rate of its utilization. In other words, the agent must weigh the marginal benefits of utilizing capital against the marginal costs of higher depreciation. As we will show later, a direct consequence of this is that the agent may find it optimal not to fully utilize capital.

The production function can be written as

$$
Y=f(\hat{K})=f(u K)
$$

where $\hat{K}=u K$ represents the flow of capital services derived from the available capital stock and $Y$ denotes the flow of output produced. We also assume that the supply of labor is inelastic and normalized to unity, so that $Y$ and $\hat{K}$ can be thought of as representing per-capita quantities. ${ }^{8}$

The specific characteristics of the production function (1) are

$$
f(u K)=A u K+\Omega(u K), \quad A \geq 0,0 \leq u \leq 1
$$

\footnotetext{
${ }^{8}$ At this point, it would be instructive to clarify the distinction between the duration and speed of operating capital equipment. Consider the following production function: $Y=d f(u K, n L)$, where $d$ represents an index of the duration of a shift, $u$ the speed of operating capital, $n$ the number of shifts, and $L$ the labor supplied in each shift. Since our aim is to isolate the effects of the rate of utilization $u$, we control for the other factors by normalizing $d=$ $n=L=1$. Therefore, we have $Y=f(u K)$; see Betancourt (1987). For a related business cycle model with variable capital utilization and endogenous labor supply, see Gilchrist and Williams (2001).
} 
where $\Omega$ satisfies the properties of a neoclassical production function. The equilibrium properties and the possibilities of sustained long-run growth from this type of production structure have been explored by Jones and Manuelli (1990); also see Barro and Sala-i-Martin (1995). Under the condition that $A=0,(2)$ reduces to the neoclassical production function, thereby ruling out the possibility of sustained long-run growth. On the other hand, when $A>0$, (2) generates short-run transitional dynamics through the behavior of $\Omega$, but in the long run converges to the "AK" type linear technology, thereby giving rise to the possibility of sustained endogenous growth. For the analytics, we assume that

$$
\Omega(u K)=(u K)^{\alpha}, 0<\alpha<1
$$

Therefore, $\alpha$ represents the output elasticity of capital. Also note that $A$, when positive, measures the long-run marginal and average product of the utilized capital stock.

The rate of depreciation of the capital stock, $\delta$, is sensitive to the choice of capital utilization. As capital is utilized more intensively, its rate of depreciation increases according to

$$
\delta(u)=\frac{1}{\phi} u^{\phi}, \quad \phi>1,0 \leq \delta(u) \leq 1
$$

where

$$
\delta^{\prime}(u)>0, \delta^{\prime \prime}(u)>0 .
$$

$\phi$ measures the elasticity of depreciation with respect to the rate of capital utilization. As $\phi \rightarrow \infty$, the sensitivity of depreciation to capital utilization declines, thereby reducing the marginal cost of utilization. In the limit, $\delta(u) \rightarrow 0$, and the marginal cost of utilizing capital is zero. This is the implicit assumption in the growth literature.

\subsection{Consumer Optimization}

The agent maximizes lifetime utility from consumption according to

$$
\int_{0}^{\infty} \frac{1}{\gamma} C^{\gamma} e^{-\beta t} d t,-\infty<\gamma<1
$$

In performing the optimization, the agent is constrained by the flow budget constraint

$$
\dot{K}=A u K+(u K)^{\alpha}-\delta(u) K-C
$$


The agent chooses the rates of consumption and capital utilization to maximize (4) subject to (5), given (2) and (3). The optimality conditions are

$$
\begin{gathered}
C^{\gamma-1}=\lambda \\
A+\alpha(u K)^{\alpha-1}=u^{\phi-1} \\
\beta-\frac{\dot{\lambda}}{\lambda}=A u+\alpha u^{\alpha} K^{\alpha-1}-\frac{1}{\phi} u^{\phi} \\
\dot{K}=A u K+(u K)^{\alpha}-\frac{1}{\phi} u^{\phi} K-C \\
\operatorname{Lim}_{t \rightarrow \infty} \lambda K e^{-\beta t}=0
\end{gathered}
$$

The interpretation of the optimality conditions (6a)-(6e) is standard. (6a) equates the marginal utility of consumption to the marginal utility of wealth, $\lambda$, which is also the co-state variable for the above problem. (6b) determines the optimal rate of capital utilization by equating its marginal benefit to marginal cost. The left-hand side represents the benefit of increasing the rate of capital utilization on the margin. However, this benefit must be traded off with its opportunity cost, in terms of the higher depreciation it entails, which is given by the right-hand side. Thus, the agent will set the rate of capital utilization at the point where the marginal production benefit equals the depreciation cost. (6c) equates the marginal return on consumption to the marginal product of capital, net of depreciation. (6d) is a restatement of the flow budget constraint, and (6e) is the familiar transversality condition.

\subsection{The Optimal Choice of the Capital Utilization Rate}

Our aim in this section is to establish two results that will be crucial to our analysis in the rest of the paper. First, we show that as long as the rate of depreciation is sensitive to capital utilization, the agent always finds it optimal to utilize capital "less than fully," i.e., $0<u<1$. Second, we explore the conditions under which the agent might find it optimal to fully utilize

capital, i.e., set $u=1$, as assumed in the existing growth literature, thereby illustrating how the 
standard growth framework can be viewed as a special case of the more general model we have set up.

To derive the above results, we focus on the equilibrium condition (6b), which determines the optimal rate of capital utilization. The left-hand side of (6b) denotes the marginal benefit of utilizing capital, for any given level of $K$, and for all $u \in[0,1]$. Let us denote this by

$$
g(u)=A+\alpha(u K)^{\alpha-1}
$$

where $g^{\prime}(u)<0, g^{\prime \prime}(u)>0, g(0)=\infty, g(1)=A+\alpha K^{\alpha-1}, g^{\prime}(0)=\infty$, and $g^{\prime}(1)<0$.

The right-hand side of (6b) denotes the marginal depreciation cost of utilizing capital, for all $u \in[0,1]$. Denote this by

$$
h(u)=u^{\phi-1}
$$

where $h^{\prime}(u)>0, h^{\prime \prime}(u)>0($ if $\phi>2), h(0)=0, h(1)=1, h^{\prime}(0)=0$, and $h^{\prime}(1)>0$.

Proposition: There exists an optimal capital utilization rate $u=u^{*} \in(0,1)$ such that $g\left(u^{*}\right)=h\left(u^{*}\right)$

Proof: Given that both $g($.$) and h($.$) are continuous and twice-differentiable functions with$ slopes of opposite sign, the proof will be complete by establishing that $g(0)>h(0)$ and $g(1)<h(1)=1$. From (6f) and $(6 \mathrm{~g})$, it can easily be established that $g(0)>h(0)$, since $g(0)=\infty$ and $h(0)=0$. To show that $g(1)<h(1)=1$, we parameterize $g(u)$ for the neoclassical and endogenous growth models. For the neoclassical growth model, $A=0$. Since (6b) is an equilibrium condition, we note that for $u=1, \alpha K^{\alpha-1}=\beta$ in steady state. Using these conditions, we see that in equilibrium, $g(1)=\beta<1$. In the endogenous growth model, with $A>0$ and sustained positive growth, $K \rightarrow \infty$. Therefore, $g(1)=A$. Imposing the mild restriction that $A<1$, we have $g(1)<1$. Therefore, there exists an optimal $u=u^{*} \in(0,1)$, such that $g\left(u^{*}\right)=h\left(u^{*}\right)$

The above result is graphically illustrated in figure 1, which plots the marginal benefit and costs of capital utilization as functions of the rate of utilization, $u$, for any given stock of capital. Marginal benefit, or $g(u)$, is shown by the downward-sloping locus MB. The marginal depreciation cost of utilization, $h(u)$, is depicted by the upward-sloping locus MC. The 
equilibrium condition (6b) ensures that the $\mathrm{MB}$ and $\mathrm{MC}$ curves intersect to yield an interior equilibrium for $u \in(0,1)$. Therefore, as long as the rate of depreciation is sensitive to the rate of capital utilization, the agent will find it optimal not to utilize capital fully.

Under what conditions, then, would it be optimal for the agent to set $u=1$, as assumed in the growth literature? To answer this question, we examine how the parameter $\phi$, which measures the sensitivity of depreciation to utilization, affects the marginal cost curve, and thereby the optimal choice of capital utilization. ${ }^{9}$ It is evident from $(6 \mathrm{~g})$ that as $\phi$ increases, the marginal cost curve MC becomes steeper and moves down to the right, since the larger is $\phi$, the lower is the sensitivity of depreciation to utilization, and hence, the lower is the marginal cost of utilization. In the limit, as $\phi \rightarrow \infty$, the marginal depreciation cost of an increase in the rate of utilization goes to zero, i.e., the depreciation rate is a constant (zero in this case), and the MC curve is a vertical line at $u=1$. MB now intersects MC at $u=1$.

\section{Capital Utilization in the Neoclassical Ramsey Model}

The optimality conditions (6a)-(6b) reduce to those of the neoclassical Ramsey model when $A=0$. Therefore, the possibility of long-run growth is ruled out in the absence of any exogenous factors like population growth or technological progress. We will thus focus our attention on the transitional adjustment path and the stationary steady state.

From (6b), we can solve for the optimal rate of capital utilization as

$$
u(K)=\left(\alpha K^{\alpha-1}\right)^{1 /(\phi-\alpha)}
$$

From (7) it is evident that the rate of utilization and the marginal product of capital are positively related. Therefore, when the marginal product of the aggregate capital stock is high, the agent will utilize it more intensively than when the marginal product is low. Substituting (7) into (3), we get the reduced-form depreciation function:

$$
\delta(K)=\frac{1}{\phi}\left(\alpha K^{\alpha-1}\right)^{\phi /(\phi-\alpha)}
$$

\footnotetext{
${ }^{9}$ Note that the MB curve is not affected by $\phi$.
} 
Therefore, both the rate of capital utilization and the rate of depreciation are increasing functions of the marginal product of capital and decreasing functions of the aggregate capital stock. ${ }^{10}$ Substituting (7) into (2a) yields the reduced form production function

$$
f(K)=\left(\alpha K^{\phi-1}\right)^{\alpha /(\phi-\alpha)} \equiv B^{\alpha} K^{\eta}
$$

where $B=\alpha^{\frac{1}{\phi-\alpha}}$ and $\eta=\frac{\alpha(\phi-1)}{\phi-\alpha}$.

$\eta$ represents the reduced-form output elasticity of the utilized capital stock. It depends on both the output elasticity of capital, $\alpha$, and the elasticity of depreciation with respect to utilization, $\phi$. Note that for $1<\phi<\infty, \eta<\alpha$ and, in the limit, as $\phi \rightarrow \infty, \eta$ approaches $\alpha$.

The core dynamics of the model, given (7) and (8), can be expressed as

$$
\begin{aligned}
& \dot{K}=B^{\alpha} K^{\eta}-\frac{1}{\phi} B^{\phi} K^{\eta}-C \\
& \dot{C}=\frac{C}{(1-\gamma)}\left(\alpha B^{\alpha} K^{\eta-1}-\frac{1}{\phi} B^{\phi} K^{\eta-1}-\beta\right)
\end{aligned}
$$

In steady-state equilibrium, we must have $\dot{K}=\dot{C}=0$. Using this condition in (10) and (11), we can solve for the steady-state level of per-capita consumption and the utilized capital stock:

$$
\widetilde{C}=\left(\frac{(\phi-\alpha) B^{\alpha}}{\phi}\right) \widetilde{K}^{\eta} ; \widetilde{K}=\left(\frac{(\phi-1) B^{\phi}}{\phi \beta}\right)^{\frac{1}{1-\eta}}
$$

Using (12a) in (7) and (8) in we can derive the steady-state capital utilization and depreciation rates:

$$
\widetilde{u}=\left(\frac{\phi \beta}{\phi-1}\right)^{\frac{1}{\phi}} ; \widetilde{\delta}=\frac{\beta}{(\phi-1)}
$$

Note that the steady-state capital utilization rate is an increasing function of $\phi$ and the depreciation rate is a decreasing function of $\phi{ }^{11}$

\footnotetext{
${ }^{10}$ Also, note from (7) and (8) that $\underset{\phi \rightarrow \infty}{\operatorname{Lim}} u(K)=1 ; \underset{\phi \rightarrow \infty}{\operatorname{Lim}} \delta(K)=0$, as proved in section 2.3.

${ }^{11}$ To ensure that $0 \leq u \leq 1$, and $0 \leq \widetilde{\delta} \leq 1$, we need to impose the following condition: $\frac{1}{1-\beta} \leq \phi<\infty$
} 
It can easily be demonstrated that the steady-state equilibrium corresponding to the dynamic system in (10) and (11) is a saddle-point with one negative and one positive root. The negative root, say $\tilde{\mu}$, which by definition is the speed of convergence to the steady-state equilibrium, is given by

$$
\tilde{\mu}=\frac{\beta-\left[\beta^{2}+\frac{4(\phi-1)(1-\eta)(\beta+\widetilde{\delta})}{\phi(1-\gamma)}\left(\frac{\beta+\widetilde{\delta}}{\alpha}-\widetilde{\delta}\right)\right]^{1 / 2}}{2}
$$

It should be noted that the convergence rate $\widetilde{\mu}$ depends not only on the preference and production parameters of the economy, but also on the output-elasticity of the utilized capital stock $(\eta)$ and consequently on the sensitivity of depreciation to capital utilization $(\phi)$, a feature absent from the traditional growth-convergence literature. It can easily be demonstrated that the convergence rate is a decreasing function of $\phi$.

The rate of growth of capital along the transition path to the steady-state equilibrium is a one-dimensional locus given by

$$
\frac{\dot{K}}{K}=\psi=\frac{1}{(1-\gamma)}\left[\alpha B^{\alpha} K^{\eta-1}-\frac{\alpha}{\phi} B^{\alpha} K^{\eta-1}-\beta\right]
$$

From (14) we see that the growth rate depends not only on the dynamic adjustment path of the marginal product of utilized capital (the first term in the parenthesis on the right-hand side), but also on the dynamic time path of the endogenous depreciation rate (the second term), which is no longer constant, as in standard growth models, but a convex function of the underlying capital stock. Diminishing returns to capital ensure that in the steady state the marginal product of capital (net of the rate of time preference) converges to the equilibrium depreciation rate, so that the steady-state growth rate is zero, i.e., $\widetilde{\psi}=0$.

The transitional dynamics of the rate of capital utilization can be obtained from (7):

$$
\psi_{u}=\frac{\dot{u}}{u}=-\left(\frac{1-\alpha}{\phi-\alpha}\right) \psi
$$

Therefore, in transition, the growth rate of capital utilization is inversely related to that of the underlying capital stock. This is consistent with the empirical findings of Nadiri and Rosen 
(1969) and Beaulieu and Mattey (1998). In the initial stages of development, when the capital stock is low, the rate of utilization is at a high level, due to the high marginal product. As capital grows towards its steady-state level, its marginal product declines, and consequently the rate of utilization declines over time towards its steady-state level.

\subsection{Implications of the Capital Utilization Decision}

We are now ready to examine the implications of the capital utilization decision for the dynamics of growth and convergence. Henceforth, we will refer to the model incorporating the capital utilization decision as the "capital utilization model," and the model that assumes constant depreciation and full (or fixed) capital utilization as the "standard model." We adopt a two-pronged strategy for our analysis. First, we would like to compare the speed of convergence and the magnitude of the steady-state equilibrium in the two models in order to isolate the longrun effect of the capital utilization decision. Second, we would like to capture solely the effect of agents' internalizing the trade-off between higher capital utilization and higher depreciation along the transition path, a feature absent from the standard growth model.

What implications does the capital utilization decision have for the steady-state equilibrium? Recalling (12a), the steady-state capital stock for the capital utilization model is given by

$$
\widetilde{K}=\left[\frac{\phi \beta}{(\phi-1) B^{\phi}}\right]^{\frac{1}{\eta-1}}=\left(\frac{\beta+\widetilde{\delta}}{\alpha^{\phi /(\phi-\alpha)}}\right)^{\frac{1}{\eta-1}}
$$

Now consider the standard neoclassical growth model with a constant depreciation rate $\bar{\delta}$. Since the depreciation rate is constant, the marginal cost of utilization is zero, and the capital utilization decision is independent of the rate of depreciation. Therefore, the agent will fully utilize capital at each instant, i.e., $\bar{u}=1, \forall t$. However, for the moment, let us relax the condition that $\bar{u}=1, \forall t$ and just assume that the rate of utilization is constant in the standard model and is equal to $u=\bar{u}, \forall t$ and $0 \leq \bar{u} \leq 1$. To make the comparison between the two models meaningful, we will first control for the steady-state depreciation rate. Therefore, in the standard model, we set $\bar{\delta}=\widetilde{\delta} \forall t$, the steady-state depreciation rate in the capital utilization model. The standard 
growth model with a constant depreciation rate $\bar{\delta}=\widetilde{\delta}$, and a fixed capital utilization rate $\bar{u}$, yields a steady-state capital stock given by

$$
\bar{K}=\left(\frac{\beta+\widetilde{\delta}}{\alpha \bar{u}^{\alpha}}\right)^{\frac{1}{\alpha-1}}
$$

Comparing (12a) and (16) and using (12b), we see that

$$
\frac{\widetilde{K}}{\bar{K}}=\left(\frac{\widetilde{u}}{\bar{u}}\right)^{\frac{\alpha}{(1-\alpha)}}
$$

Therefore, as long as $\widetilde{u} \neq \bar{u}, \widetilde{K} \neq \bar{K}$. In the standard model, the implicit assumption is that the rate of capital utilization is one, i.e., $\bar{u}=1, \forall t$. Under this condition, (17) implies that $\widetilde{K}<\bar{K}$. However, in the limit, as $\phi \rightarrow \infty, \widetilde{u} \rightarrow 1$, and $\widetilde{K} \rightarrow \bar{K}$. Similar arguments apply for consumption and output. The higher transitional depreciation costs due to the agent's optimal choice of the time path of capital utilization lead to lower new investment, and as a consequence, a lower steady-state per-capita capital stock, consumption, and output than those implied by the standard growth model, where the rate of capital utilization is fixed at unity. Therefore, by ignoring the optimal choice of capital utilization, the standard one-sector growth model may be overstating the magnitude of the steady-state equilibrium. The numerical simulations we conduct in section 5 will further illustrate the magnitude of this overstatement.

What effect does the agents' internalization of the costs and benefits of capital utilization have on the speed of convergence to the steady-state equilibrium? Recalling (13), the speed of convergence in the capital utilization model is given by

$$
\tilde{\mu}=\frac{\beta-\left[\beta^{2}+\frac{4(\phi-1)(1-\eta)(\beta+\widetilde{\delta})}{\phi(1-\gamma)}\left(\frac{\beta+\widetilde{\delta}}{\alpha}-\widetilde{\delta}\right)\right]^{1 / 2}}{2}
$$

The speed of convergence implied by the standard model with a constant utilization rate $(u=\bar{u} \leq 1, \forall t)$ is 


$$
\bar{\mu}=\frac{\beta-\left[\beta^{2}+\frac{4(1-\alpha)(\beta+\widetilde{\delta})}{(1-\gamma)}\left(\frac{\beta+\widetilde{\delta}}{\alpha}-\widetilde{\delta}\right)\right]^{1 / 2}}{2}
$$

Notice that in (18), the speed of convergence in the standard model is independent of the fixed rate of capital utilization, $\bar{u}$. Therefore, as long as the rate of capital utilization is constant, its value will have no bearing on the speed of convergence. As a result, (18) would apply both to the standard model with $\bar{u}<1 \forall \mathrm{t}$, and with $\bar{u}=1 \forall t$. On the other hand, the speed of convergence in the capital utilization model depends on $\eta$, the output elasticity of utilized capital, as well as $\phi$, the sensitivity of depreciation to capital utilization. Comparing (13) and (18), we see that as long as $1<\phi<\infty$, and consequently $\eta<\alpha$, we must have $|\widetilde{\mu}|<|\bar{\mu}|$. In the limit, as $\phi \rightarrow \infty, \eta \rightarrow \alpha$, and $|\widetilde{\mu}| \rightarrow|\bar{\mu}|$. Therefore, the optimal choice of capital utilization slows down the rate at which an economy approaches its steady-state equilibrium.

The intuition behind the above result can be explained as follows. A direct consequence of incorporating the decision to utilize capital on the margin is an endogenous depreciation rate whose time path depends on that of capital. Specifically, from (8) we see that

$$
\delta(K)=\frac{B^{\phi}}{\phi K^{1-\eta}} .
$$

Therefore, the depreciation rate is a decreasing and convex function of the capital stock. As the capital stock approaches its steady-state level, the capital utilization and depreciation rates gradually decline to their respective steady-state values, given by (12b). Then, for any level of capital stock $K<\widetilde{K}$, we must have $\delta(K)>\widetilde{\delta}=\bar{\delta}$. This is shown in figure 2. The higher depreciation rate in transition requires a larger proportion of new investment to be devoted to maintaining the existing stock of capital. This reduces the amount of new investment every period, and as a consequence slows down the speed of convergence to the steady-state. In contrast, a fixed depreciation rate and capital utilization rate during transition imply a zero marginal cost of utilization, and higher new investment, and consequently, a higher speed of convergence. 
The model we have developed in this paper supports the notion of conditional convergence, i.e., the possibility that structurally similar countries with similar initial conditions will converge to a common steady-state per-capita income. It is also evident from our analysis that the rate of capital utilization is a potential determinant of conditional convergence. Even though international evidence of capital utilization is sparse, studies by Bautista et al. (1981) and Anxo et al. (1995) document large variations in the workweek of capital, both in manufacturing and non-manufacturing industries, across countries and continents. The framework we have developed takes the notion of conditional convergence one step further by showing that differences in the degree to which agents internalize the capital utilization decision along the transition path may lead to differences in the speed of "catching up," even for countries with similar structural and initial conditions. To illustrate this possibility, we start by controlling for the steady-state equilibrium. From (17) we see that if we control for the steady-state capital utilization rates in the two models, i.e., if $\tilde{u}=\bar{u}$, then $\widetilde{K}=\bar{K}$ and consequently, $\widetilde{Y}=\bar{Y}$. We now have an example of two countries that have similar structural characteristics and initial conditions and therefore a common per-capita level of income. As an extreme illustration, even though both countries have the same long-run capital utilization rates, we have one country where agents internalize the utilization decision along the transition path (the capital utilization model), and another where this decision is not internalized (the standard model). Then, by comparing (13) and (18), we can see that these two countries, starting from the same initial conditions, will approach their common steady-state per-capita income at different speeds of convergence. Stated differently, the greater the extent of internalization of the capital utilization decision, the longer it will take for a country to reach its steady-state equilibrium.

\section{Capital Utilization in the Endogenous Growth Model}

To obtain sustained long-run endogenous growth, we will now revert to the case where $A$ $>0$. This implies that the marginal product of capital is bounded from below in the long run, and provided that, net of depreciation costs, it exceeds the rate of time preference, the model generates sustained positive long-run growth. Since both the per-capita capital stock and 
consumption grow continuously in the long-run equilibrium, we must express the steady-state equilibrium and the dynamics in terms of stationary variables.

Let $y=f(u K) / K$, the average product of utilized capital, and $c=C / K$, the consumption-capital ratio, be the stationary variables in terms of which we shall express the equilibrium dynamics. We can then rewrite the first-order conditions (6b) and (6c) as

$$
\begin{gathered}
\alpha y+(1-\alpha) A u=u^{\phi} \\
\beta-\frac{\dot{\lambda}}{\lambda}=\alpha y+(1-\alpha) A u-\frac{1}{\phi} u^{\phi}
\end{gathered}
$$

(19a) can be solved to yield the optimal rate of capital utilization as a function of the average product of capital:

$$
u=u(y)
$$

where $u^{\prime}(y)>0$ and $u^{\prime \prime}(y)<0$.

The core dynamics of the model can be expressed as

$$
\begin{gathered}
\dot{y}=-\frac{\phi(1-\alpha)(y-A u)}{(\phi-1)}\left[\frac{1}{\phi}\{(\phi-\alpha) y-(1-\alpha) A u\}-c\right] \\
\frac{\dot{c}}{c}=\frac{1}{(1-\gamma)}\left[\left(\frac{\phi-1}{\phi}\right)\{\alpha y+(1-\alpha) A u\}-\beta\right]-\frac{1}{\phi}[(\phi-\alpha) y-(1-\alpha) A u]+c \\
\frac{\dot{u}}{u}=-\frac{(1-\alpha)(y-A u)}{(\phi-1)\{\alpha y+(1-\alpha) A u\}}\left[\frac{1}{\phi}\{(\phi-\alpha) y-(1-\alpha) A u\}-c\right]
\end{gathered}
$$

The steady state is attained when $\dot{y}=\dot{c}=\dot{u}=0$. The steady-state equilibrium can be described by

$$
\begin{gathered}
\widetilde{c}=\frac{1}{(1-\gamma)}\left[\beta-\frac{\gamma(\phi-1)}{\phi} A \widetilde{u}\right] \\
\widetilde{u}=(\widetilde{y})^{1 / \phi}=A^{1 /(\phi-1)} \\
\tilde{y}=A \widetilde{u}=A^{\phi(\phi-1)} \\
\widetilde{\delta}=\frac{1}{\phi} \widetilde{y}=\frac{1}{\phi} A \widetilde{u}=\frac{1}{\phi} A^{\phi((\phi-1)}
\end{gathered}
$$


Therefore, in the steady-state equilibrium, the average product of capital and the rate of capital utilization converge to constant levels, determined by the long-run marginal product of capital and the sensitivity of depreciation to capital utilization. The steady-state balanced growth rate is given by

$$
\widetilde{\psi}=\frac{1}{(1-\gamma)}\left[\left(\frac{\phi-1}{\phi}\right) A \widetilde{u}-\beta\right]=\frac{1}{(1-\gamma)}[A \widetilde{u}-\widetilde{\delta}-\beta]
$$

It can be verified that the steady-state equilibrium is a saddle-point with one positive and one negative eigenvalue. The negative eigenvalue, which measures the speed of convergence, can be expressed as

$$
\widetilde{\mu}=-\frac{(1-\alpha)}{(1-\gamma)}\left[\left(\frac{\phi-1}{\phi}\right) A \widetilde{u}-\beta\right]
$$

Note that, in contrast to the neoclassical growth model, the speed of convergence in the endogenous growth model is a function of the steady-state rate of capital utilization. Further, it is an increasing function of the sensitivity of depreciation to utilization, $\phi$. This is also in contrast to the neoclassical model, where the relationship was exactly the opposite. This is because of long-run constant returns to scale in utilized capital in the endogenous growth model. From (21b)-(21d), we see that an increase in $\phi$, in addition to decreasing the depreciation rate, also increases the long-run marginal and average product of capital, thereby increasing the steady-state rate of utilization and flow of new investment. This tends to increase the speed of convergence.

\subsection{Implications of the Capital Utilization Decision}

Since the steady-state equilibrium levels and the speed of convergence in the endogenous growth model are proportional to the steady-state rate of capital utilization, we will compare the capital utilization model with the standard model with full capital utilization, i.e., $\bar{u}=1 \forall t .{ }^{12}$ As

\footnotetext{
${ }^{12}$ This comparison is dictated by the nature of the production function assumed which, for the endogenous growth model, reduces to the linear "AK" model in the long run. In a more general model with two capital stocks, as in Ortiguera and Santos (1997), it will be possible to isolate the effect of capital utilization on the convergence path by controlling for the steady-state equilibrium.
} 
in section 3, we compare the two alternative models by controlling for the long-run depreciation rate.

In the standard model with a constant depreciation rate $\bar{\delta}=\widetilde{\delta} \forall t$, the long-run growth rate is given by $\bar{\psi}=\frac{1}{(1-\gamma)}[A-\widetilde{\delta}-\beta]$. Comparing this with (22), we see that

$$
\widetilde{\psi}-\bar{\psi}=\frac{A}{(1-\gamma)}(\widetilde{u}-1)<0 .
$$

We can derive similar expressions for the equilibrium output-capital and consumption-capital ratios in the two models:

$$
\begin{aligned}
\tilde{y}-\bar{y} & =A(\widetilde{u}-1)<0 \\
\widetilde{c}-\bar{c} & =-\frac{\gamma A}{(1-\gamma)}[(\widetilde{u}-1)]<0 \text { if } \gamma<0 .
\end{aligned}
$$

Comparing the absolute values of the speed of convergence from (23) with that from the standard model, we get

$$
|\widetilde{\mu}|-|\bar{\mu}|=\frac{(1-\alpha) A}{(1-\gamma)}(\widetilde{u}-1)<0
$$

Therefore, as in the previous section, ignoring the capital utilization decision leads the standard endogenous growth model to overstate the magnitude of the steady-state equilibrium and the speed of convergence.

\section{Capital Utilization and Convergence: A Numerical Analysis}

We now proceed to a numerical illustration of the implications of endogenous capital utilization for the neoclassical and endogenous growth models. We begin by specifying the parameterization of our benchmark economy.

\section{Benchmark Economy}

\begin{tabular}{|ll|}
\hline Preference parameters: & $\beta=0.04, \gamma=-1.5$ \\
Production parameters: & $\begin{array}{l}A=0,0.3 ; \alpha=1 / 3 \\
1<\phi<\infty\end{array}$ \\
\hline
\end{tabular}

The above benchmark specification assigns numerical values to the structural parameters of the economy consistent with corresponding empirical estimates. The rate of time preference 
$\beta$ is 0.04 and $\gamma$, which is a measure of the intertemporal elasticity of substitution, is -1.5 . On the other hand, the production parameters are parameterized so as to yield either the neoclassical or the endogenous growth model. For example, $A$ is equal to 0.3 in the endogenous growth model, but is equal to zero in the neoclassical model. The output elasticity of aggregate capital, $\alpha$, is equal to about 0.3 , consistent with estimates of the share of capital in U.S. GDP. Finally, $\phi$, which measures the sensitivity of the depreciation rate to capital utilization, is allowed to vary from above 1, yielding a high equilibrium depreciation rate, to infinity, where the depreciation rate goes to zero.

The approach we will adopt is in line with the theoretical comparisons outlined in sections 3 and 4 . For any given $\phi$, the capital utilization model gives the equilibrium capital utilization rate $\tilde{u}$, the equilibrium depreciation rate $\widetilde{\delta}$, and the corresponding speed of convergence to this equilibrium, along with other equilibrium quantities such as per-capita output, consumption, capital stock, and growth rates. We then calibrate the standard growth model using the equilibrium solutions obtained from the capital utilization model. The implied speeds of convergence and other relevant equilibrium quantities from the two models are then compared by varying $\phi$ from above one to infinity.

\subsection{The Neoclassical Growth Model}

Table 1 presents a numerical comparison of the speed of convergence between the standard growth model and the capital utilization model. ${ }^{13}$ In performing this comparison, we use two insights obtained from our theoretical analysis. First, from (13) and (18), we see that the speed of convergence is independent of the steady-state rate of capital utilization. Second, (17) shows that the steady-state equilibrium levels depend on the equilibrium capital utilization rate. Therefore, to make the comparison meaningful, we control for the fixed capital utilization and depreciation rates in the standard model, i.e., for any $\phi$, we set $\bar{u}=\widetilde{u}, \bar{\delta}=\widetilde{\delta}, \forall t$, where $\bar{u}$ and $\bar{\delta}$ are the corresponding variables in the standard model. In other words, we calibrate the

\footnotetext{
${ }^{13}$ As noted before, we set $A=0$ in the general production function (2) in order to analyze the neoclassical case.
} 
standard model with a constant capital utilization rate and depreciation rate, where these rates are equal to those obtained from the equilibrium solution to the capital utilization model. Then, the two models will have the same steady-state equilibrium, and the only difference between them would be that in one model the choice of capital utilization is internalized along the transition to the steady state, while in the other it is not. Our numerical calculations will then reveal the effect of this internalization (or the lack of it) on the speed of convergence in the two models.

Our starting point in table 1 is $\phi=1.5$. The capital utilization model yields an equilibrium utilization rate of 24 percent and a depreciation rate of 8 percent. The speed of convergence to the stationary steady state is about 4.5 percent. On the other hand, the standard model with capital utilization and depreciation rates fixed at 24 percent and 8 percent respectively yields a much higher speed of convergence of 7.68 percent, to the same steady-state equilibrium. For the entire range of $\phi$ considered (between 1.5 and infinity), the capital utilization model always yields a speed of convergence lower than that implied by the standard model. However, in the limit, when $\phi \rightarrow \infty, \widetilde{\delta} \rightarrow 0, \tilde{u} \rightarrow 1$, the two models converge. Interestingly, for $\phi \geq 2.5$, with implied depreciation rates between 0 and 2.5 percent, and utilization rates above 34 percent, the speed of convergence from the capital utilization model lies within the range of 2-3 percent, which corresponds to the recent empirical estimates obtained by Barro and Sala-i-Martin (1992, 1995), Mankiw, Romer and Weil (1992), and Sala-i-Martin (1994, 1996). For example, for $\phi=3$, the capital utilization model yields an equilibrium utilization rate of 39 percent and depreciation rate of 2 percent. The corresponding speed of convergence is 2.82 percent, in line with recent empirical estimates. In comparison, the corresponding standard growth model yields a speed of convergence of 3.44 percent, which is outside the empirical range. As $\phi$ becomes large, the decreasing marginal cost of capital utilization reduces the gap between the standard model and the capital utilization model, and in the limit, as the two models converge to the same equilibrium, the speed of convergence in each model approaches 2.1 percent. 
To illustrate the effect of the agents' internalization of the capital utilization decision on the convergence path, we conduct the following numerical experiment, the results of which are depicted in figure 3. For the purpose of the experiment, we set $\phi=1.5$, which yields an equilibrium capital utilization rate of 24 percent and a depreciation rate of 8 percent. Since the equilibrium capital utilization and depreciation rates depend on $\beta$ and $\phi$ (see (12b)), we can set the same initial conditions in both models. We consider a ceteris paribus increase in $\alpha$, the output elasticity of the aggregate capital stock, from its benchmark value of 0.3 to 0.5 . Figure 3A plots the transitional dynamics of the output-capital ratio $(Y / K)$ in response to this productivity shock in the two models. Since we control for initial and steady-state conditions, both models converge to a common output-capital ratio in the long run. However, there are some fundamental differences in their transitional adjustment paths. First, our numerical calculations reveal that the speed of convergence in the capital utilization model following the shock is 2.82 percent, while that in the standard model is 4.51 percent. This implies that in the model where the capital utilization decision is internalized along the transition path, the half-life of convergence is about 25 years, while in the standard model, where the capital utilization rate is fixed, the corresponding half-life is only about 15 years. ${ }^{14}$ Second, the instantaneous responses following the increase in $\alpha$ across the two models are exactly opposite. In the standard model, with fixed capital utilization and a given initial stock of capital, an increase in $\alpha$ leads to an instantaneous fall in the average product of capital. In contrast, in the capital utilization model, an increase in $\alpha$ increases the marginal benefit of capital utilization and, given an initial level of capital stock, leads to an instantaneous increase in its rate of utilization, from 24 percent to 35 percent, as shown in figure 3B. As a result, the average product of capital increases instantaneously. Thereafter, as capital accumulation takes place, the output-capital ratio falls over time in both models till it converges to a common steady-state level (the standard

\footnotetext{
${ }^{14}$ The time $t$ for which the output-capital ratio is halfway between its initial and final steady-state values is given by the condition $e^{-\mu t}=0.5$, where $\mu$ is the absolute value of the speed of convergence; see Barro and Sala-i-Martin (1995, p. 37).
} 
model gets their earlier than the capital utilization model). After its initial jump, $u$ gradually decreases over time (see figure 3B) in the capital utilization model, while in the standard model it remains constant. Further, the higher rate of capital utilization along the transition path yields a higher output-capital ratio in the capital utilization model than in the standard model at every instant along the adjustment path. This example, though a little simplistic and extreme, illustrates that variations in the degree to which agents internalize the capital utilization decision may provide a better understanding of convergence paths and speeds across countries.

Table 2 reports the relative differences in equilibrium levels between the standard model, which implicitly assumes full utilization, i.e., $\bar{u}=1, \forall t$, and the capital utilization model, where the equilibrium rate of utilization need not be one, i.e., $\tilde{u}<1 .{ }^{15}$ For example, when $\phi=1.5$ and $\widetilde{\delta}=8$ percent, the standard model (with $\bar{u}=1$ ) overstates equilibrium per-capita output by about 51 percent and the speed of convergence by about 41 percent relative to the capital utilization model. However, as the marginal cost of utilization decreases (i.e., as $\phi$ increases) and the equilibrium capital utilization rate increases towards unity, the relative difference between the equilibrium levels in the two models diminishes. In the limit, as $\phi \rightarrow \infty$ and $\tilde{u} \rightarrow 1$, the two models converge to the same steady-state equilibrium.

Tables 1 and 2 illustrate the significance of capital utilization for growth. First, our numerical calculations show that the introduction of capital utilization as an optimal decision can help explain the slow speeds of convergence observed in empirical tests. Second, it underscores the importance of the internalization of the capital utilization decision along the transition path to the long-run equilibrium. Finally, it suggests that by not allowing for the optimal choice of capital utilization, the standard growth model may be overstating the magnitude of the long-run equilibrium.

\footnotetext{
${ }^{15}$ Specifically, let $\tilde{X}$ be an equilibrium variable in the capital utilization model and $\bar{X}$ be the corresponding variable in the standard model. Then, the relative difference between the two equilibrium levels is given by $(1-\tilde{X} / \bar{X})$.
} 


\subsection{The Endogenous Growth Model}

Tables 3 and 4 present similar numerical exercises for the endogenous growth model, and further reinforce the results obtained in the previous section. However, since the steady-state equilibrium in this model has the property that all steady-state quantities, including the speed of convergence, are proportional to the steady-state rate of capital utilization, we can only compare the standard model, which sets $\bar{u}=1, \forall t$ with the capital utilization model with $\tilde{u}<1$, by controlling only for the steady-state rate of depreciation. For this experiment, we set $A$ equal to its benchmark value of 0.3 . Table 3 presents the differences in the speed of convergence between the standard and capital utilization models, and table 4 presents the relative differences in the equilibrium levels between the two models, for different values of $\phi$.

As in the neoclassical model, we find that for any equilibrium rate of depreciation, the speed of convergence in the standard endogenous growth model is always greater than that obtained from the capital utilization model. For example, in table 3 when $\phi=3.5$, the equilibrium rate of capital utilization is 62 percent, and the corresponding rate of depreciation is 5.3 percent. The implied speed of convergence from this model is 2.46 percent, which is within the empirically estimated range. On the other hand, the standard model with a fixed depreciation rate of 5.3 percent and the rate of utilization set to unity predicts a speed of convergence of 5.52 percent, which is much higher than empirical estimates. Also, note that for the entire range of $\phi$ and $\widetilde{\delta}$ considered, the speed of convergence in the standard model varies from 5.5 percent to about 6.9 percent, well above the empirically plausible range. On the other hand, the capital utilization model yields speeds of convergence from about 1.1 percent to 6.9 percent, which, for a wide range of parameter values $(1<\phi<4.5)$, fall well within the empirical range of 2-3 percent.

Table 4 highlights the fact that the assumption of fixed depreciation and full capital utilization may lead to a significant overstatement of the steady-state equilibrium in the endogenous growth model. For example, when $\phi=2.5$, and the equilibrium depreciation and capital utilization rates equal 5.8 percent and 45 percent respectively, the standard model 
overstates the output-capital ratio by about 55 percent, the consumption-output ratio by 12 percent, and the long-run growth rate and the speed of convergence by about 80 percent. As in the case of the neoclassical economy, the relative difference between the equilibrium levels in the two models diminishes as capital utilization becomes less costly on the margin and the utilization rate increases towards unity. In the limit, as $\phi \rightarrow \infty$ and $\tilde{u} \rightarrow 1$, the two models yield identical equilibrium levels.

\section{Conclusions}

This paper introduces capital utilization as an optimal choice in a general class of onesector models of economic growth. Our objective has been to bring theoretical predictions regarding the speed of convergence obtained from one-sector growth models in line with observed empirical estimates. We show that incorporating the capital utilization decision into a standard growth model may help to resolve the discrepancy between theory and facts, and provide a simpler alternative, based on optimal choice, to the adjustment cost and multiple capital good frameworks. Contrary to the assumptions of theoretical growth models, the sensitivity of depreciation to capital utilization leads to "less than full" utilization of capital by the economic agent, a result consistent with empirical facts. The relationship between the rate of depreciation and capital utilization, embodied in the variable marginal benefits and costs of capital accumulation along the transition path, plays a crucial role in slowing down the speed of convergence to the steady-state equilibrium. We also show that by assuming a constant depreciation rate and full capital utilization, the standard growth models may be significantly overstating the magnitude of both the steady-state equilibrium and the convergence rate. Finally, our numerical analysis suggests that differences across countries in the extent to which agents internalize the capital utilization decision along the transition path may lead to differences in the speed of adjustment to the steady state, even for countries that have similar structural and initial conditions.

By underscoring the importance of capital utilization for the dynamics of growth and convergence, our analysis not only attempts to bring theory closer to the facts, but also opens up 
potential avenues for future research in this area. The framework we have developed suggests that research on economic growth should pay more attention not only to the aggregate capital stock as an engine of growth, but also to the flow of services derived from it, through the capital utilization decision. This opens up the question of understanding and separating the long-run determinants of the choice of the workweek of capital from that of labor, examining how that choice is affected by public policy and, in turn, how it affects the growth-convergence path of an economy. 


\section{References}

Aizcorbe, A.M., (1994), "Plant Shutdowns, Compositional Effects, and Procyclical Labor Productivity: The Stylized Facts for Auto Assembly Plants.” FEDS Working Paper \# 9413 (June), Board of Governors of the Federal Reserve.

Anxo, D., G. Bosch, D. Bosworth, G. Cette, T. Sterner, and D. Taddei, (1995), Work Patterns and Capital Utilization. Boston: Kluwer Academic Publications.

Barro, R.J., (1991), "Economic Growth in a Cross Section of Countries." Quarterly Journal of Economics, 106(2), pp. 407-443.

Barro, R.J., and X. Sala-i-Martin, (1992), “Convergence.” Journal of Political Economy, 100(2), pp. 223-251.

Barro, R.J., and X. Sala-i-Martin, (1995), Economic Growth. New York: McGraw Hill.

Barro, R.J., and X. Sala-i-Martin, (1997), “Technological Diffusion, Convergence, and Growth.” Journal of Economic Growth, 2(1).

Bautista, R.M., H. Hughes, D. Lim, D. Morawetz, and F.E. Thoumi, (1981), Capital Utilization in Manufacturing. Washington, DC: Oxford University Press.

Beaulieu, J.J., and J. Mattey (1998), "The Workweek of Capital and Capital Utilization in Manufacturing." Journal of Productivity Analysis, 10, pp. 199-223.

Bernard, A.B., and C.I. Jones, (1996), “Technology and Convergence.” Economic Journal, 106, pp. $1037-1044$.

Betancourt, R.R. (1987), “Capital Utilization” in J. Eatwell, M. Milgate, and P. Newman (ed.), The New Palgrave: A Dictionary of Economics. The Stockton Press.

Betancourt, R.R., and C.K. Clague, (1981), Capital Utilization: A Theoretical and Empirical Analysis. UK: Cambridge University Press.

Bresnahan, T.F., and V.A. Ramey, (1993), "Segment Shifts and Capacity Utilization in the U.S. Automobile Industry.” AEA Papers and Proceedings, May, pp. 213-218. 
Bresnahan, T.F., and V.A. Ramey, (1994), "Output Fluctuations at the Plant Level.” Quarterly Journal of Economics, CIX(3), pp. 593-624.

Burnside, C., M. Eichenbaum, and S. Rebelo, (1996), "Capital Utilization and Returns to Scale." NBER Macroeconomics Annual, 11, pp. 67-123.

Calvo, G.A., (1975), "Efficient and Optimal Utilization of Capital Services." American Economic Review, 65(1), pp. 181-186.

Cardellichio, P.A., (1990), "Estimation of Production Behavior using Pooled Microdata." Review of Economics and Statistics, 72(1), pp. 11-18.

Caselli, F., G. Esquivel, and F. Lefort, (1996), "Reopening the Convergence Debate: A New Look at Cross-Country Empirics.” Journal of Economic Growth, 1, pp. 363-390.

Eicher, T.S., and S.J. Turnovsky, (1999a), "Non-Scale Models of Economic Growth.” Economic Journal, 109, pp. 394-415.

Eicher, T.S., and S.J. Turnovsky, (1999b), "Convergence Speeds and Transitional Dynamics in Non-Scale Growth Models." Journal of Economic Growth, 4, pp. 413-428.

Epstein, L.G., and M. Denny, (1980), "Endogenous Capital Utilization in a Short-Run Production Model: Theory and Empirical Application." Journal of Econometrics, pp. 189207.

Evans, P., (1997), “How Fast do Countries Converge?” Review of Economics and Statistics, 79, 219-225.

Foss, M.F., (1963), “The Utilization of Capital Equipment: Postwar Compared with Pre-war.” Survey of Current Business, 43, pp. 8-16.

Foss, M.F., (1981a), "Long-run Changes in the Workweek of Fixed Capital." AEA Papers and Proceedings 71(2), pp. 58-63.

Foss, M.F., (1981b), Changes in the Workweek of Fixed Capital: US Manufacturing, 1929 to 1976. Washington, DC: American Enterprise Institute. 
Foss, M.F., (1995), “Operating Hours of U.S. Manufacturing Plants, 1976-1988, and their Significance for Productivity Change." In Anxo et al., Work Patterns and Capital Utilization. Boston: Kluwer Academic Publications.

Gilchrist, S., and J.C. Williams (2001), "Transition Dynamics in Vintage Capital Models: Explaining the Postwar Catch-Up of Germany and Japan.” Mimeo, Boston University.

Greenwood, J., Z. Hercowitz, and G.W. Huffman, (1988), "Investment, Capacity Utilization, and the Real Business Cycle.” American Economic Review, 78(3), pp. 402-417.

Hsieh, C., (2001), "Endogenous Growth and Obsolescence." Journal of Development Economics, 66, pp. 153-171.

Islam, N., (1995), "Growth Empirics: A Panel Data Approach.” Quarterly Journal of Economics, 110, pp. 1127-1170.

Jones, L.E., and R. Manuelli, (1990), “A Convex Model of Equilibrium Growth: Theory and Implications.” Journal of Political Economy, 98(5), pp. 1008-1038.

Keynes, J.M., (1936), The General Theory of Employment, Interest and Money. London: Macmillan.

Kollintzas, T., and J.B. Choi, (1985), “A Linear Rational Expectations Equilibrium Model of Aggregate Investment with Endogenous Capital Utilization and Maintenance.” Mimeo, State University of New York.

Kydland, F.E., and E.C. Prescott, (1982), "Time-to-Build and Aggregate Fluctuations." Econometrica, 50, pp. 1345-1370.

Lucas, R.J., (1970), “Capacity, Overtime, and Empirical Production Functions.” American Economic Review, 60(2), pp. 23-27.

Lucas, R.J., (1988), "On the Mechanics of Economic Development.” Journal of Monetary Economics, 22, pp. 3-42.

Mankiw, N.G., D. Romer, and D. Weil, (1992), “A Contribution to the Empirics of Economic Growth." Quarterly Journal of Economics, 107, pp. 407-438.

Marris, R., (1964), The Economics of Capital Utilization. UK: Cambridge University Press. 
Nadiri, M.I., and I.R. Prucha, (1996), "Estimation of the Depreciation Rate of Physical and R\&D Capital in the U.S. Total Manufacturing Sector.” Economic Inquiry, 34, pp. 43-56.

Nadiri, M.I., and S. Rosen, (1969), "Interrelated Factor Demand Functions." American Economic Review, 59, pp. 457-471.

Oi, W., (1981), "Slack Capacity: Productive or Wasteful.” American Economic Review, Papers and Proceedings, 71, pp. 64-69.

Orr, J.A., (1989), “The Average Workweek of Capital in Manufacturing, 1952-84.” Journal of the American Statistical Association, 84 (405), pp. 88-94.

Ortiguera, S., and M.S. Santos, (1997), "On the Speed of Convergence in Endogenous Growth Models." American Economic Review, 87(3), pp. 383-399.

Sala-i-Martin, X., (1994), "Cross-Sectional Regressions and the Empirics of Economic Growth." European Economic Review, 38, pp. 739-747.

Sala-i-Martin, X., (1996), "The Classical Approach to Convergence Analysis." Economic Journal, 106, pp. 1019-1036.

Shapiro, M.D., (1986), “Capital Utilization and Capital Accumulation: Theory and Evidence." Journal of Applied Econometrics, 1, pp. 211-234.

Smith, K.R., (1970), "Risk and the Optimal Utilization of Capital." Review of Economic Studies, 37, pp. 253-259.

Taubman, P., and M. Wilkinson, (1970), "User Cost, Capital Utilization and Investment Theory.” International Economic Review, 11(2), pp. 209-215.

Taubman, P., and P. Gottschalk, (1971), "The Average Workweek of Capital in Manufacturing." Journal of the American Statistical Association, 66 (335), pp. 448-455.

Temple, J.R.W., (1998), "Robustness Test of the Augmented Solow Model.” Journal of Applied Econometrics, 13, pp. 361-375.

Turnovsky, S.J., (2000), Methods of Macroeconomic Dynamics. Cambridge: The MIT Press, Second Edition. 
Turnovsky, S.J., (2003), “The Transitional Dynamics of Fiscal Policy: Long-run Capital Accumulation and Growth." Forthcoming, Journal of Money, Credit and Banking.

Wen, Y., (1998), “Capacity Utilization under Increasing Returns to Scale.” Journal of Economic Theory, 81, pp. 7-36. 
Figure 1. The Optimal Choice of the Capital Utilization Rate

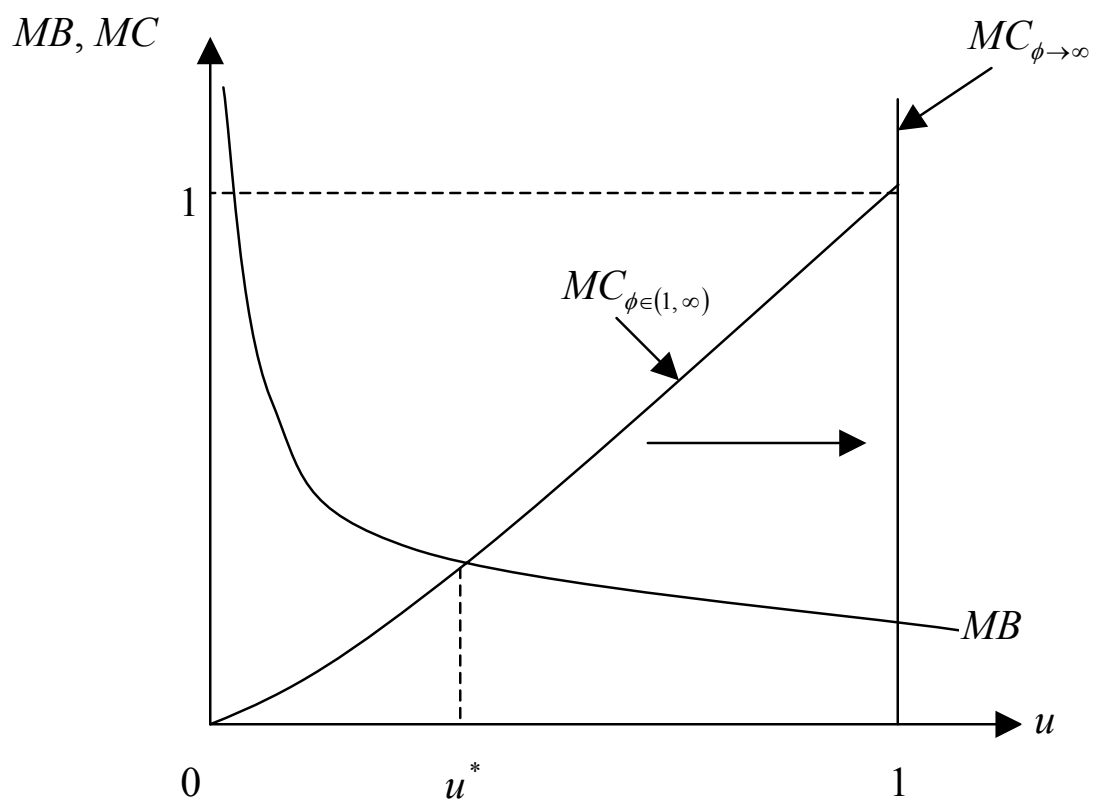

Figure 2. Depreciation Rates and Capital Utilization in the Ramsey Model

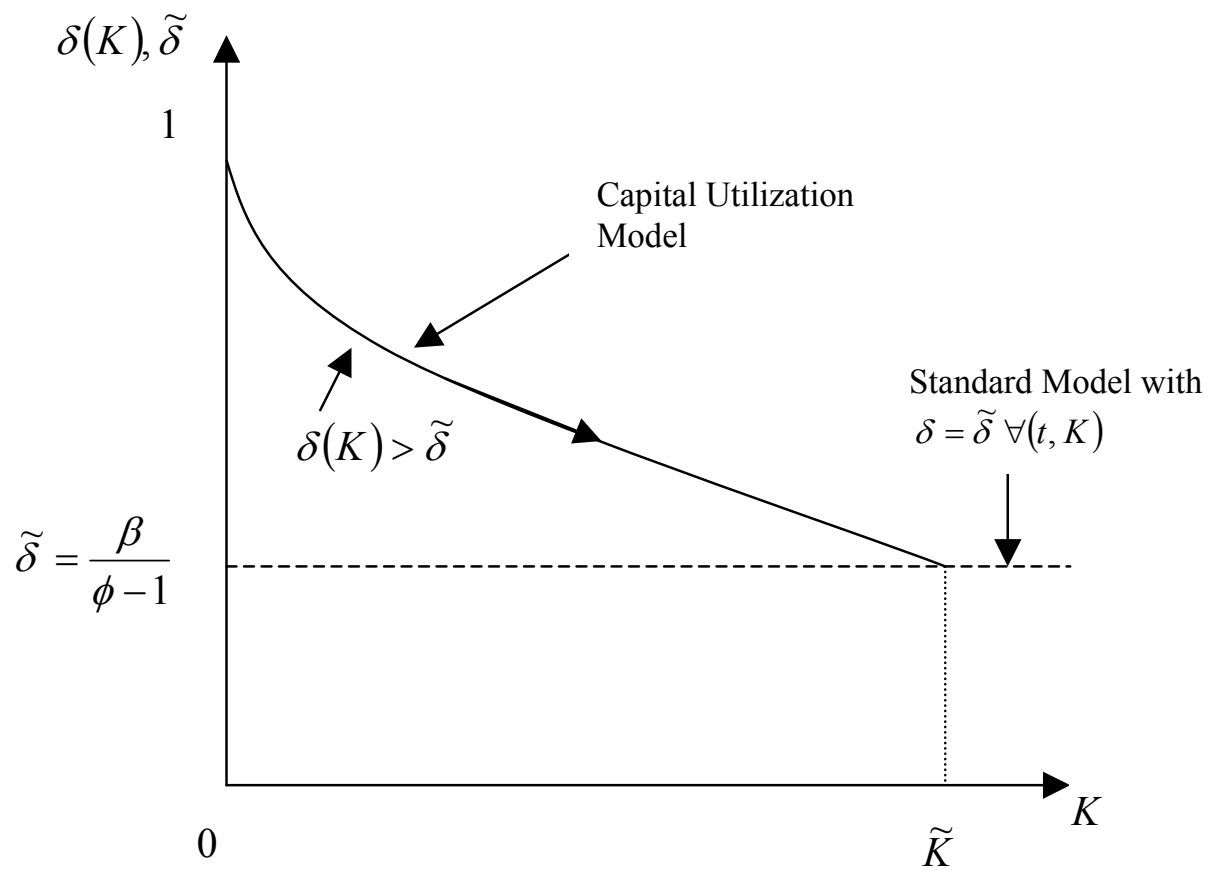


Figure 3. Increase in $\alpha$ in the Capital Utilization and Standard Growth Models`

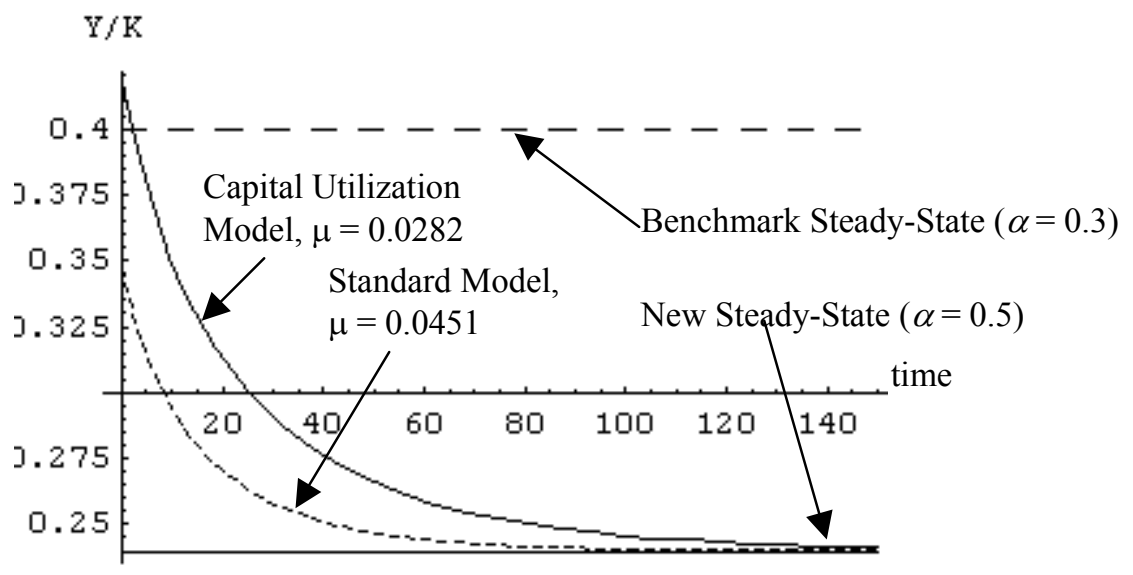

A. The Convergence Path

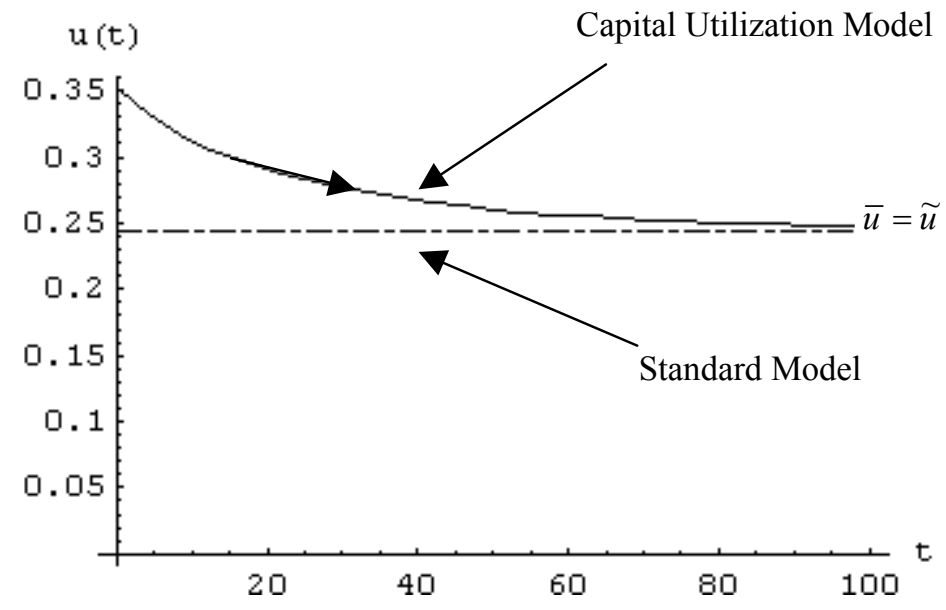

B. The Rate of Capital Utilization 
Table 1. The Neoclassical Growth Model

Speed of Convergence

\begin{tabular}{|c|c|c|}
\hline & $\begin{array}{l}\text { Standard Model } \\
\bar{\delta}=\widetilde{\delta}, \bar{u}=\widetilde{u} \forall t\end{array}$ & $\begin{array}{c}\text { Capital Utilization } \\
\text { Model } \\
u=u(K(t)), 0<\tilde{u} \leq 1\end{array}$ \\
\hline $\begin{array}{c}\phi=1.5 \\
\widetilde{\delta}=0.08, \widetilde{u}=0.24\end{array}$ & 0.0768 & 0.0451 \\
\hline $\begin{array}{c}\phi=2 \\
\widetilde{\delta}=0.04, \tilde{u}=0.28\end{array}$ & 0.0483 & 0.0344 \\
\hline $\begin{array}{c}\phi=2.5 \\
\widetilde{\delta}=0.027, \tilde{u}=0.34\end{array}$ & 0.0390 & 0.0303 \\
\hline $\begin{array}{c}\phi=3 \\
\widetilde{\delta}=0.02, \tilde{u}=0.39\end{array}$ & 0.0344 & 0.0282 \\
\hline $\begin{array}{c}\phi=3.5 \\
\widetilde{\delta}=0.016, \widetilde{u}=0.44\end{array}$ & 0.0317 & 0.0268 \\
\hline $\begin{array}{c}\phi=4 \\
\widetilde{\delta}=0.0133, \tilde{u}=0.48\end{array}$ & 0.0298 & 0.0259 \\
\hline $\begin{array}{c}\phi=4.5 \\
\widetilde{\delta}=0.011, \widetilde{u}=0.52\end{array}$ & 0.0286 & 0.0252 \\
\hline $\begin{array}{c}\phi=5 \\
\widetilde{\delta}=0.01, \tilde{u}=0.55\end{array}$ & 0.0276 & 0.0247 \\
\hline $\begin{array}{c}\phi=6 \\
\widetilde{\delta}=0.008, \widetilde{u}=0.60\end{array}$ & 0.0263 & 0.0240 \\
\hline $\begin{array}{c}\phi=12 \\
\widetilde{\delta}=0.0036, \tilde{u}=0.77\end{array}$ & 0.0235 & 0.0224 \\
\hline $\begin{array}{c}\phi \rightarrow \infty \\
\widetilde{\delta} \rightarrow 0, \tilde{u} \rightarrow 1\end{array}$ & 0.0210 & 0.0210 \\
\hline
\end{tabular}

Note: $\widetilde{X}=$ Equilibrium quantity in the capital utilization model $\bar{X}=$ Equilibrium quantity in the standard model 
Table 2. The Steady-State in the Neoclassical Growth Model: A Comparison of the Standard Model $(u=1)$ with the Capital Utilization Model $(0<u<1)$

Relative Differences in Equilibrium Levels

\begin{tabular}{|c|c|c|}
\hline & $\begin{array}{l}\text { Per-Capita } \\
\text { Output } \\
(1-\widetilde{Y} / \bar{Y})\end{array}$ & $\begin{array}{c}\text { Speed of } \\
\text { Convergence } \\
(1-\widetilde{\mu} / \bar{\mu})\end{array}$ \\
\hline $\begin{array}{c}\phi=1.5 \\
\widetilde{\delta}=0.08, \tilde{u}=0.24\end{array}$ & 0.5078 & 0.4122 \\
\hline $\begin{array}{c}\phi=2 \\
\widetilde{\delta}=0.04, \widetilde{u}=0.28\end{array}$ & 0.4682 & 0.2879 \\
\hline $\begin{array}{c}\phi=2.5 \\
\widetilde{\delta}=0.027, \widetilde{u}=0.34\end{array}$ & 0.4182 & 0.2223 \\
\hline $\begin{array}{c}\phi=3 \\
\widetilde{\delta}=0.02, \tilde{u}=0.39\end{array}$ & 0.3743 & 0.1814 \\
\hline $\begin{array}{c}\phi=3.5 \\
\widetilde{\delta}=0.016, \tilde{u}=0.44\end{array}$ & 0.3376 & 0.1532 \\
\hline $\begin{array}{c}\phi=4 \\
\widetilde{\delta}=0.013, \tilde{u}=0.48\end{array}$ & 0.3068 & 0.1326 \\
\hline $\begin{array}{c}\phi=4.5 \\
\widetilde{\delta}=0.011, \tilde{u}=0.52\end{array}$ & 0.2809 & 0.1169 \\
\hline $\begin{array}{c}\phi=5 \\
\widetilde{\delta}=0.01, \tilde{u}=0.55\end{array}$ & 0.2589 & 0.1046 \\
\hline $\begin{array}{c}\phi=6 \\
\widetilde{\delta}=0.008, \tilde{u}=0.60\end{array}$ & 0.2236 & 0.0864 \\
\hline $\begin{array}{c}\phi=12 \\
\widetilde{\delta}=0.004, \tilde{u}=0.77\end{array}$ & 0.1223 & 0.0422 \\
\hline $\begin{array}{c}\phi \rightarrow \infty \\
\widetilde{\delta} \rightarrow 0, \tilde{u} \rightarrow 1\end{array}$ & 0 & 0 \\
\hline
\end{tabular}

Note: $\tilde{X}=$ Equilibrium quantity in the capital utilization model $\bar{X}=$ Equilibrium quantity in the standard model 
Table 3. The Endogenous Growth Model Speed of Convergence

\begin{tabular}{|c|c|c|}
\hline & $\begin{array}{l}\text { Standard Model } \\
\bar{\delta}=\widetilde{\delta}, \bar{u}=1 \forall t\end{array}$ & $\begin{array}{c}\text { Capital Utilization } \\
\text { Model } \\
u=u(K(t)), 0<\tilde{u} \leq 1\end{array}$ \\
\hline $\begin{array}{c}\phi=2.5 \\
\widetilde{\delta}=0.058, \tilde{u}=0.45\end{array}$ & 0.0550 & 0.0108 \\
\hline $\begin{array}{c}\phi=3.0 \\
\widetilde{\delta}=0.055, \widetilde{u}=0.55\end{array}$ & 0.0547 & 0.0186 \\
\hline $\begin{array}{c}\phi=3.5 \\
\widetilde{\delta}=0.053, \widetilde{u}=0.62\end{array}$ & 0.0552 & 0.0246 \\
\hline $\begin{array}{c}\phi=4 \\
\widetilde{\delta}=0.05, \tilde{u}=0.67\end{array}$ & 0.0560 & 0.0295 \\
\hline $\begin{array}{c}\phi=4.5 \\
\widetilde{\delta}=0.0473, \tilde{u}=0.71\end{array}$ & 0.0567 & 0.0335 \\
\hline $\begin{array}{c}\phi=5 \\
\widetilde{\delta}=0.0444, \tilde{u}=0.74\end{array}$ & 0.0575 & 0.0367 \\
\hline $\begin{array}{c}\phi=5.5 \\
\widetilde{\delta}=0.0417, \tilde{u}=0.77\end{array}$ & 0.0582 & 0.0394 \\
\hline $\begin{array}{c}\phi=6 \\
\widetilde{\delta}=0.0393, \tilde{u}=0.79\end{array}$ & 0.0589 & 0.0417 \\
\hline $\begin{array}{c}\phi=12 \\
\widetilde{\delta}=0.0224, \widetilde{u}=0.90\end{array}$ & 0.0634 & 0.0551 \\
\hline $\begin{array}{c}\phi \rightarrow \infty \\
\widetilde{\delta} \rightarrow 0, \tilde{u} \rightarrow 1\end{array}$ & 0.0693 & 0.0693 \\
\hline
\end{tabular}

Note: $\widetilde{X}=$ Equilibrium quantity in the capital utilization model $\bar{X}=$ Equilibrium quantity in the standard model 
Table 4. The Steady-State in the Endogenous Growth Model: A Comparison of the Standard Model $(u=1)$ with the Capital Utilization Model $(0<u<1)$

Relative Differences in Equilibrium Levels

\begin{tabular}{|c|c|c|c|c|}
\hline & $\begin{array}{c}\text { Output- } \\
\text { Capital } \\
\text { Ratio } \\
(1-\tilde{y} / \bar{y})\end{array}$ & $\begin{array}{c}\text { Consumption } \\
\text {-Output } \\
\text { Ratio } \\
\left(1-\frac{\tilde{c} / \tilde{y}}{\bar{c} / \bar{y}}\right)\end{array}$ & $\begin{array}{c}\text { Growth } \\
\text { Rates } \\
(1-\tilde{\psi} / \bar{\psi})\end{array}$ & $\begin{array}{l}\text { Speed of } \\
\text { convergence } \\
\quad(1-\tilde{\mu} / \bar{\mu})\end{array}$ \\
\hline $\begin{array}{c}\phi=2.5 \\
\widetilde{\delta}=0.058, \widetilde{u}=0.45\end{array}$ & 0.5533 & 0.1227 & 0.8024 & 0.8036 \\
\hline $\begin{array}{c}\phi=3.0 \\
\widetilde{\delta}=0.055, \tilde{u}=0.55\end{array}$ & 0.4533 & 0.0864 & 0.6614 & 0.6599 \\
\hline $\begin{array}{c}\phi=3.5 \\
\widetilde{\delta}=0.053, \tilde{u}=0.62\end{array}$ & 0.3833 & 0.0585 & 0.5531 & 0.5544 \\
\hline $\begin{array}{c}\phi=4 \\
\widetilde{\delta}=0.05, \tilde{u}=0.67\end{array}$ & 0.3333 & 0.0364 & 0.4732 & 0.4732 \\
\hline $\begin{array}{c}\phi=4.5 \\
\widetilde{\delta}=0.0473, \tilde{u}=0.71\end{array}$ & 0.3000 & 0.0357 & 0.4101 & 0.4092 \\
\hline $\begin{array}{c}\phi=5 \\
\widetilde{\delta}=0.0444, \tilde{u}=0.74\end{array}$ & 0.2667 & 0.0351 & 0.3608 & 0.3617 \\
\hline $\begin{array}{c}\phi=6 \\
\widetilde{\delta}=0.0393, \widetilde{u}=0.79\end{array}$ & 0.2000 & 0.0172 & 0.2911 & 0.2920 \\
\hline $\begin{array}{c}\phi \rightarrow \infty \\
\widetilde{\delta} \rightarrow 0, \tilde{u} \rightarrow 1\end{array}$ & 0 & 0 & 0 & 0 \\
\hline
\end{tabular}

Note: $\widetilde{X}=$ Equilibrium quantity in the capital utilization model $\bar{X}=$ Equilibrium quantity in the standard model 